\title{
Being Canadian with a global dimension
}

\author{
Subrata Ghosh MD (Edin) FRCP FRCPE FRCPC
}

$\mathrm{I}^{\mathrm{a}}$ am privileged and honoured to take on the role of the new Editor-in-Chief in an era when the future of medical journals is a topic of considerable debate. Similar to books, its demise has been predicted regularly, and yet books have made a resilient and vigorous comeback. There is no doubt that medical journals must meet the fast-paced requirements of providing high-quality, peer-reviewed information, but medical journals do more than just that. A medical journal may be the glue that holds a medical community or society together, and often reflects its principles and goals. A national journal often reflects the unique nature of training and practice of the country, and a window to its innovation, research and vibrancy. It often engages in debates - scientific or political - and strives to bring about changes in the quality and safety of clinical practice for the benefit of patients. The success of a medical journal hinges on its readability and clarity of message, its dissemination and distribution, its impact factor and, finally, its financial viability. While impact factor is an important benchmark, it alone does not reflect the quality of a journal. My vision is that of a new invigorated era of scientific publishing, in which electronic and paper publishing integrate seamlessly.

The role of the Editor-in-Chief is to lead a dynamic team by communicating clear policies, promoting team ownership of common goals, and to spearhead changes through performance reviews and surveys of its readership. The Canadian Association of Gastroenterology (CAG), the Canadian Association for the Study of the Liver (CASL), the publisher (Pulsus Group Inc), the editorial team, the editorial board and, especially, the readership, contribute to the success of the Journal and will be its important stakeholders. A journal that finds its way into a briefcase to be read in the office or on a flight is often successful, but this success depends on an attractive format, clear messages in text boxes and a variety of relevant articles serving the spectrum of readership, including the CAG and CASL membership. Electronic and paper formats complement each other, and their strengths can be used together. Electronic format permits additional information and details, videos and photographs as well as links to additional information; it is also easily upgradeable. Electronic format holds promise for open exchange of medical information without barriers. Paper format can present clear messages in a more concise fashion, with better reading satisfaction.

Attracting high-quality manuscripts is the key to making The Canadian Journal of Gastroenterology/Le Journal canadien de gastroenterologie successful and popular. A key role would be to promote and present excellence in gastrointestinal and hepatology research in Canada. A wide and dynamic editorial board can often be proactive in attracting manuscripts, especially from promising rising stars in Canada. In addition, an international 'presence' in the editorial board would also attract international authors, especially those with Canadian connections. Canada plays an important role in providing high-quality gastroenterology and hepatology training to fellows worldwide, and the Journal can play a pivotal role in promoting its training excellence. Review articles and focused-topic reviews can provide valuable education and information if such articles pertain to novel topics not well covered in the existing literature. These articles and, especially, systematic reviews, are important in raising the impact factor of a journal because they tend to be well cited, and enhance the education and training of gastroenterology fellows. In identifying such topics, the synergy between the CAG/CASL education committee and the Journal editorial team would be invaluable, and key members of the education committees will form an important component of the editorial board. An international editorial board will help this further by identifying the most appropriate expert(s) to address a cutting-edge topic. Canadian care pathways and practice guidelines are important drivers of change and are always well cited - these form an integral part of a national journal. Topical controversies and debates are invigorating and promote a culture of introspection and analysis - they are also entertaining and increase the readability of journals. A culture of debate can also be promoted by 'Letters to the Editor' that are related to articles published in the journal and editorials on important topics. Readability is also increased by avoiding detailed case reports and, instead, presenting a short 'Image of the Month', with perhaps more

University of Calgary, Calgary, Alberta

Correspondence: Dr Subrata Ghosh, Division of Gastroenterology, Teaching, Research and Wellness Centre, 3280 Hospital Drive Northwest,

Calgary, Alberta T2N 4Z6. Telephone 403-592-5010, fax 403-592-5080, e-mail ghosh@ucalgary.ca

Received and accepted for publication December 17, 2009 
details in electronic format that could form a library of educational cases. In this manner, the Journal may become an important element of key message boxes and bullet points, further enhancing the readability and retention of educational messages. In addition, a rapid and high-quality review process, and a quick online publication will help attract good, quality articles.

Medical quality assurance and initiatives measuring quality and promoting changes are key roles of the CAG/CASL. These are important research and debate areas, and The Canadian Journal of Gastroenterology can feature this as an important focus area, with a designated section editor. Articles focused on these issues influence public policies and health initiatives, and the Journal can become known for showcasing research and development in these areas nationally and internationally. The important scientific advances of today are of translational benefit to patients tomorrow. It is vital that gastroenterologists and hepatologists are aware of important scientific advances, and understand their principles so that patients ultimately benefit from their application advances in stem cell therapy and in monoclonal antibody development are good examples. The Journal will present selected and easily readable articles on important scientific advances expected to impact patient care in a significant manner.

I expect The Canadian Journal of Gastroenterology to have a broad readership among the diversity of members of the CAG/CASL, as well as community practitioners, alternative care providers and pharmacists caring for patients with gastrointestinal disorders. Responsiveness to the requirements of the stakeholders will permit the Journal to remain fresh and vibrant. I look forward to the challenge and your comments.

Finally, great thanks to Dr Paul Adams for leading this Journal so ably for five years and effecting the many changes that have improved the Journal and increased its impact factor. I am grateful for his advice and several suggestions regarding the Journal, and I hope to benefit from his experience in my first few years. He will be a hard act to follow.

\section{KEY ELEMENTS OF THE VISION}

1. Attract high-quality manuscripts reflecting Canadian and international clinical research, especially from rising stars.

2. Identify, invite and publish novel systematic reviews and focused reviews on hot topics not well represented in the literature, in discussion with CAG/CASL education committees.

3. Use the strengths of electronic and paper formats in synergy. Replace detailed case reports by an 'Image of the Month', with videos and extra photographs in electronic format.

4. Major focus on quality assurance issues, care pathways and guidelines as a continuing theme.

5. Closely align the CAG/CASL, the editorial team and the readership regarding common goals and vision. 


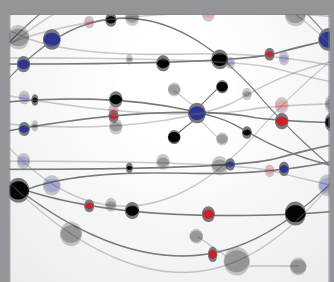

The Scientific World Journal
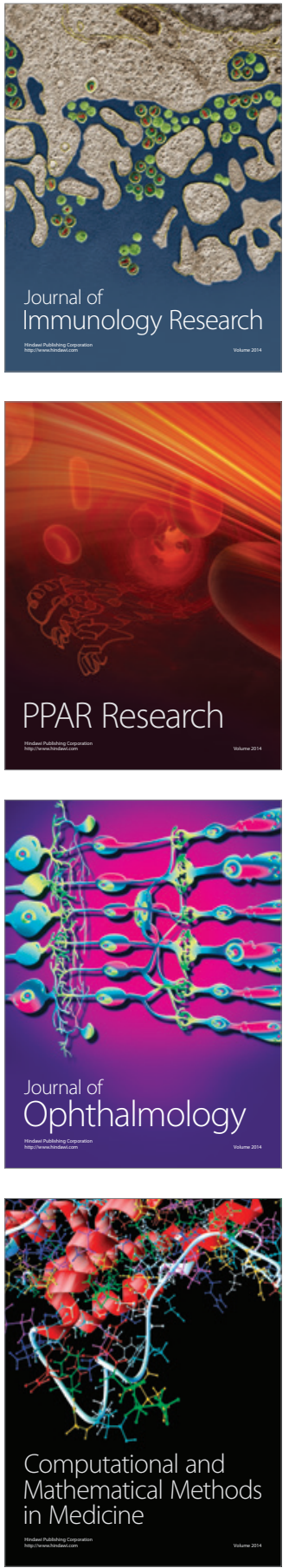

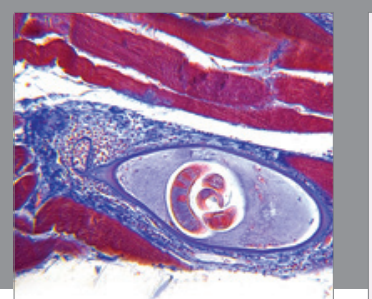

Gastroenterology Research and Practice

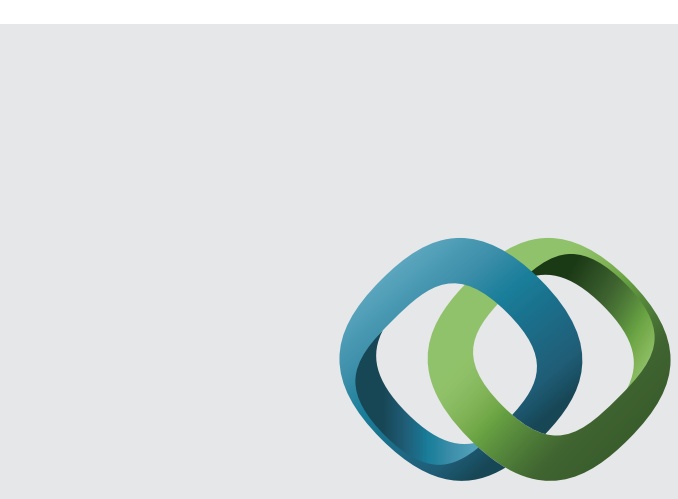

\section{Hindawi}

Submit your manuscripts at

http://www.hindawi.com
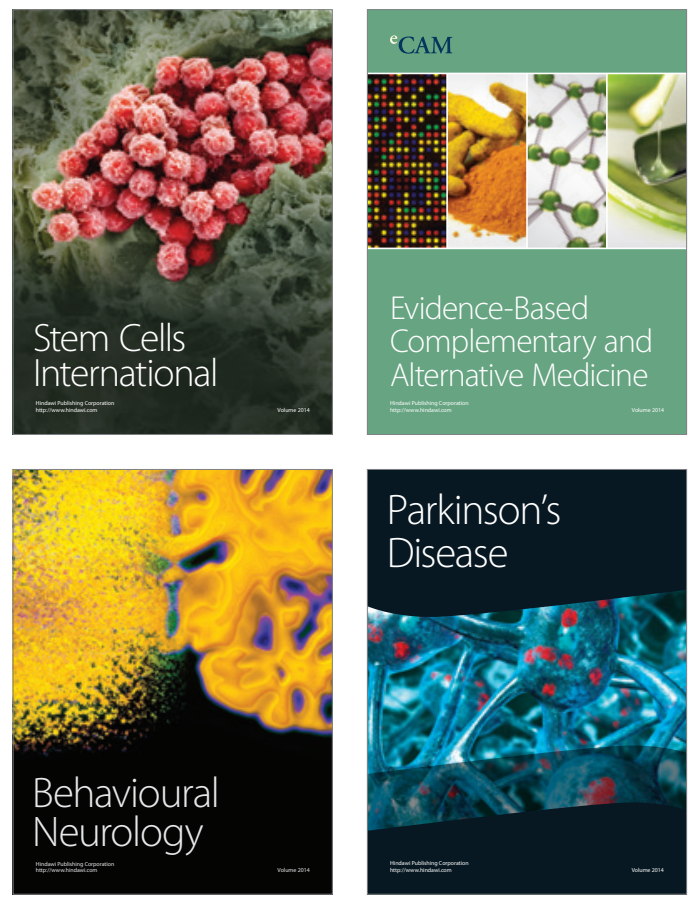
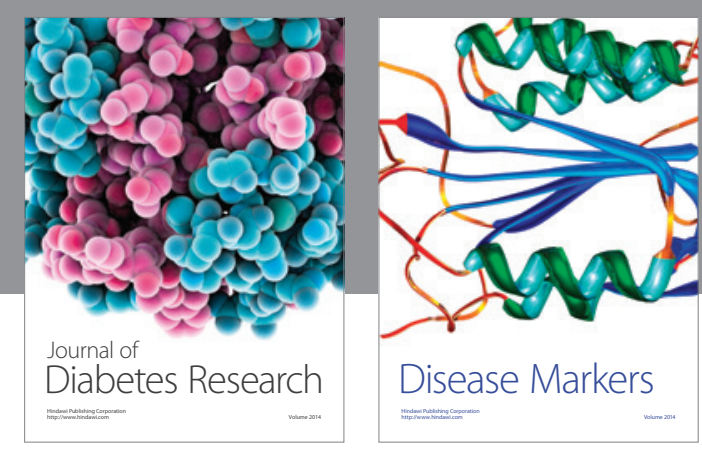

Disease Markers
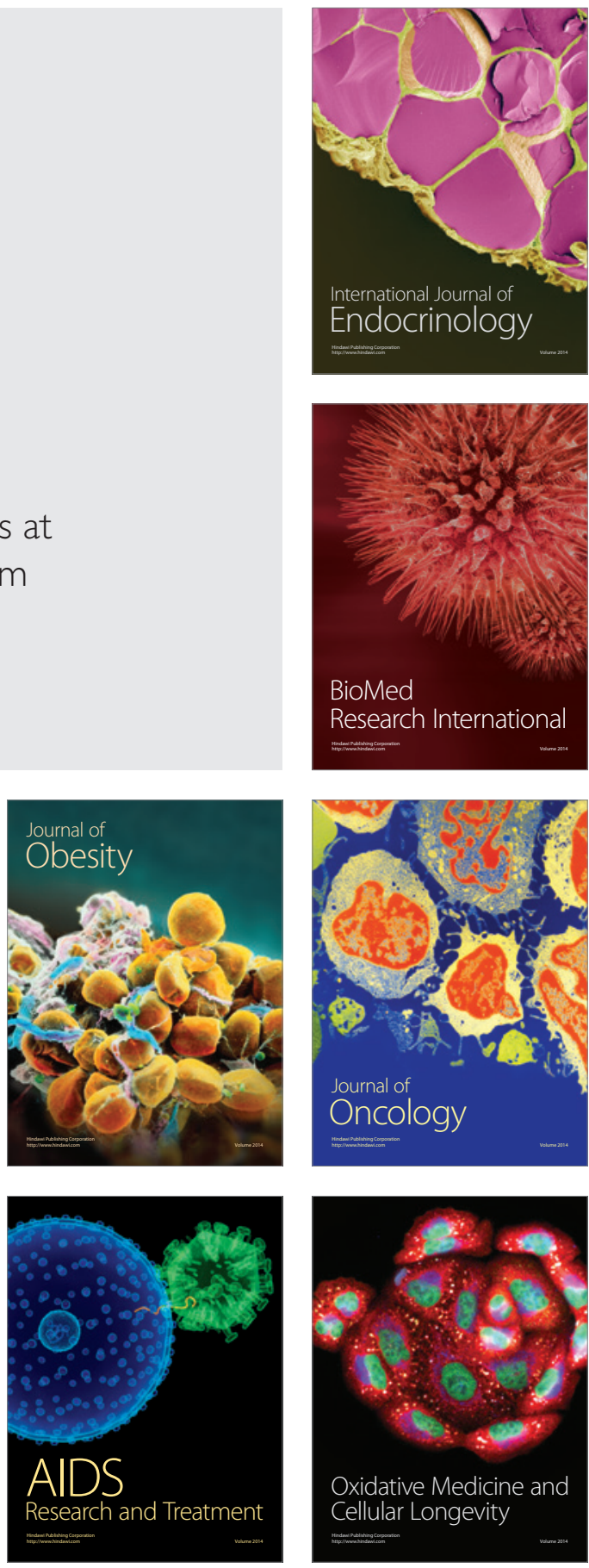